\author{
Al-wardah: Jurnal Kajian Perempuan, Gender dan Agama \\ Volume : 13 No 1. Edisi Juni 2019 \\ ISSN: 1907-2740, E-ISSN: 2613-9367 \\ DOI: $10.46339 /$ al-wardah.v13i1.161
}

\title{
Wanita Karir Dalam Pandangan Islam
}

\author{
Ismiyati Muhammad \\ Guru MAN Model Ternate, Indonesia \\ ismiyati@gmail.com
}

\begin{abstract}
Abstrak
Wanita Karir berarti wanita yang memiliki pekerjaan dan mandiri finansial baik kerja pada orang lain atau punya usaha sendiri. Ia identik dengan wanita pintar dan perempuan modern. Ketiga label ini bisa positif tapi juga negatif tergantung bagaimana dia bisa membawa diri secara agama dan sosial. Islam datang mengangkat harkat wanita setara dengan kaum pria dalam hakekat kemanusiannya dan mendapatkan hak-hak yang wajar sebagaimana kaum pria. Seiring dengan berubahnya cara pandang masyarakat terhadap peran dan posisi kaum wanita di tengah masyarakat.Kesimpulan dari makalah ini adalah Islam adalah agama yang sangat fleksibel dan mengerti terhadap perempuan namun tetap mempunyai aturan mainnya sendiri. Dimana wanita karir dalam Islam memang diperbolehkan asalkan mendapatkan ijin dari suami dan bekerja untuk membantu keluarga, ini akan jadi sebuah kegiatan yang menyenangkan apalagi jika didasari oleh ibadah.
\end{abstract}

Kata Kunci. : Wanita Karir, Pandangan Islam

\begin{abstract}
Abstrac
Career woman means a woman who has a job and is financially independent both working for someone else or having her own business. He is synonymous with smart women and modern women. These three labels can be positive but also negative depending on how he can carry himself religiously and socially. Islam came to uphold the dignity of women as equals to men in their human nature and to obtain the natural rights as men. Along with the changing perspective of society on the role and position of women in society. The conclusion of this paper is that Islam is a very flexible religion, understands women but still has its own rules of the game. Career women in Islam are allowed as long as they get permission from their husbands and work to help the family, this will be a fun activity if it is based on worship.
\end{abstract}

Keywords. : Career Woman, Islamic View 


\section{A. Pendahuluan}

Isu ketidak adilan gender mulai disuarakan sejak tahun isu ketidak adilan gender mulai disuarakan di Indonesia sejak 1960- an, isu ini menjadi bagian dari fenomena dan dinamika masyarakat Indonesia yang membuat posisi kaum perempuan semakin membaik. Ditengah hembusan gerakan feminisme, sebagai akibat dari kebutuhan untuk menghidupi keluarga dan semakin meningkatnya pendidikan kaum hawa .

Dewasa ini peluang dunia pendidikan bagiperempuan semakin besar.Hampir semua jenjangdanjenispendidikan bisa dimasuki perempuan. Hampir-hampir tidak lagi ditemukan pendidikankhususbagilaki- lakikecualipendidikan dipesantren.Semua jurusandanprogram studi, yang disediakan mulaidari humaniora sampaitehnik mesin bisa dimasuki setiap orang tanpa membedakanjenis kelamin.

Secara tidak senggaja kebebasan ini, ternyata memberipeluang kepada perempuanuntuk bisa bersaing dalammemperolehlapangan pekerjaan.Hal ini karena pendidikan yang dianggap sebagai label untuk memperoleh pekerjaan, telahmembuatsejarah barudalamkehidupan moderen. Orang dianggap cakap, mampu, dan layak diterima dalam suatu pekerjaan karena jejnajng pendidikannya yang semakin tinggi

Disebabkan keberhasilandalamproses pendidikan, ataukemampuan akademik yang diukur oleh pencapaian Indeks Prestasi Kumulatif (IPK) dijadikan pula sebagai ukuran untuk pertimbangan dalam menerima calon pekerja. Ditambah lagi, keberhasilan dalam proses pendidikan, atau kemampuan akademik yang dilambangkan dengan adanya Indeks Prestasi Kumulatif (IPK) justru dijadikan pula sebagai ukuran untuk pertimbangan dalammenerima calon pekerja.

Kondisi ini telah menggeser persaingan untuk mendapatkan pekerjaan menjadi persaingan untuk memperoleh tempat dalam dunia pendidikan.Merebut peluang dalam dunia pendidikan jauh lebih objektif, ilmiah, serta tidak deskriminatif terhadap gender. 
Inilah yang termasuk dalam salah satu prinsip pokok ajaran Islam yaitu persamaan hak antar manusia, baik antara pria maupun wanita, bangsa, suku, dan keturunan. Perbedaan diantara mereka dihadapan Tuhan Yang Maha Esa hanyalah nilai pengabdian dan ketakwaannya.

\section{B. Pembahasan}

Wanita karier yang disibukan dengan bekerja diluar rumah sering diistilahkan dengan wanita karier .Istilah "karier" dari segi bahasa adalah sebuah istilah yang tidak hanya mencakup keikut sertaan pada lapangan kerja tetapi lebih merupakan kesukaan atau ketertarikan pada pekerjaan upahan dalam waktu lama, atau paling tidak mendambakan kemajuan dan peningkatan dalam waktu tertentu. Selain itu, karir dapat diartikan dengan"serangkaian pilihan dan kegiatan pekerjaan yang menunjukkan apa yang dilakukan oleh seseorang untuk dapat hidup.

Dari kedua pernyataan diatas dapat disimpulkan bahwa Wanita Karir berarti wanita yang memiliki pekerjaan dan mandiri finansial baik kerja pada orang lain atau punya usaha sendiri.Ia identik dengan wanita pintar dan perempuan modern.Ketiga label ini bisa positif tapi juga negatif tergantung bagaimana dia bisa membawa diri secara agama dan sosial.

Dalam al-Qur'an banyak ayat -ayat yang menunjukkan bahwa pria dan wanita adalalah semartabat sebagai manusia, terutama secara spiritual. Toha Husein, dalam bukunya yang berjudul, al-Fitnatu al-Kubra, menjelaskan tiga prinsip dasar yang dibawa Nabi Muhammad yaitu keadilan (al-adalah), persamaan (al-musawa) dan musyawarah (al-syura').

Di dalam ajaran Islam, perempuan adalah mahluk yang dimuliakan.maka dari itu Islam sangat menjaga hak-hak perempuan, apakah itu hak untuk memperoleh pendidikan maupun hak untuk memperoleh pekerjaan dan berkarir. Jauh sebelum gerakanemansipasidangender memperjuangkan hak-hak perempuan dalam pendidikan dan pekerjaan, ajaran Agama Islam telah memulainya terlebih dahulu. 
Disinilah ahirnyamunculkomunitaspekerja perempuan atauyang lebih populerdisebut dengan wanita karier. Wanita karier memperluas dunia pengabdiannya,bukan saja sebagai ibu rumah tangga (perandomestik),melainkan ada juga di tengah masyarakat dengan jabatan (peran publik).

Pendapat masyasrakat yang ada selama ini beranggapan bahwa setinggi-tinggi perempuan sekolah, akhirnya akan ke dapur juga sudah mulai ditinggalkan,bahkan sudah mulai dibongkar. Pekerjaan dapur tidak lagi dipahami dalam arti kerja yang husus untuk perempuan seperti memasak,mengasuh anak, dan mengatur rumah tangga serta melayani suami di kasur. Dapur sudah mengalami pergeseran penafsiran dengan memasuki penafsiran metafora,yakni kewajiban membantu ekonomi keluarga dan membantu membiayairumah tangga.

Namun fungsi sebagai wanita karier ini ternyata tidaklah semulus apa yang kita bayangkan jabatan sebagai wanita karier tidak pernah lepas dari persoalan. Persoalan tersebut antara lain adalah tentang pengasuhan dan membimbing anak.Secara emosional dan secara psycologis anak lebih dekat kepada ibunya, ketimbang kepada bapaknya.Oleh sebab itu ketergantungan anak terhadap ibu sebagai pengasuh, pendidik, serta yang mengawasi perkembangan anak sejak kecil hingga dewasa diletakkan pada ibu. Sementara ayah bekerja diluar rumah.Maka bila ibu bekerja di lluar rumah itu berarti perhatian terhadapanak menjadi berkurang.

Seiring dengan berubahnya cara pandang masyarakat terhadap peran dan posisi kaum wanita di tengah-tengah masyarakat, maka kini sebagaimana kaum pria banyak kaum wanita yang berkarir, baik di kantor pemerintah maupun swasta bahkan ada yang berkarir di bidang kemiliteran dan kepolisian, sebagaimana pria. Dalam kehidupan modern banyak wanita dapat bekerja dan berkarir dimana saja selagi adakesempatan. Ada yang berkarir dalam hukum dan jaksa. Ada yang terjun di bidang ekonomi, seperti menjadi pengusaha, pedagang, kontraktor dan sebagainya. Ada pula yang bergerak di bidang sosial budaya dan pendidikan, seperti menjadi dokter, arsitek, artis, penyanyi, sutradara, guru, dan lain-lain. Bahkan ada pula yang terjun dalam bidang politik, misalnya menjadi presiden, anggota DPR, MPR, DPA, Menteri dan lain-lain 
Keterangan di atas menunjukkan besarnya peran wanita dalam dunia kerja tetapi dunia kerja sangat tidak ramah terhadap wanita, salah satunya dengan menempatkan mereka pada posisi sekunder seperti di pabrik sepatu dimana wanita hanya bertugas memasukkan sepatu dalam kardus. Sedang posisi primer atau yang penting dalam sebuah perusahaan selalu dipegang oleh pria. Wanita ditempatkan pada posisi sekunder karena munculnya anggapan wanita cenderung lebih pasif dan memiliki intelektual lebihrendah dibanding dengan pria. Hal tersebut mengakibatkan pekerjaan yang hanya membutuhkan ketekunan, ketelitian, dan kerapihan, dan biasanya hanya mengerjakan satujenis pekerjaan setiap hari selama bertahun-tahun.

Pandangan yang merendahkan terhadap wanita sangat mempengaruhi mereka dalam dunia kerja seperti mereka harus menerima tindak pelecehan seksual di tempat mereka bekerja baik dari rekan kerjanya sendiri ataupun dengan atasannya, gaji rendah yang mereka peroleh dikarenakan wanita mengalami haid, hamil, melahirkan sehingga tidak mampu beraktivitas dengan semaksimal mungkin. Perusahaan tidak memberikan wanita jaminan kesehatan yang memadai kalaupun ada tidak semua wanita akan memperolehnya

Problem lain adalah kerumah tanggaan. Dengan istri yang berkarier sering diasumsikan akan mengganggu keharmonisan rumah tangga. Meninggalkan rumah karena sibuk bekerja,bisa memicu konflik rumah tangga. dirumah yang didambakan oleh suami ketika ia pulang dari pekerjaan,akan tidak didapat lagi bila istrinya masih bekerjadi luar rumah.

Ajaran Islam sangat menganjurkan perempuan untuk menjaga keluarga dan rumah tangganya,tetapi hal tersebu ttidak menghalanginya berperan aktif dalam membangun dan memberdayakan masyarakat bersama-sama dengan lelaki dalam kehidupan nyata tanpa melalaikan tugas sebagai ibu rumah tangga dan menjaga rumahtangga nya agar tetap terpoenuhi layaknya ibu rumah tangga yang lain.

Islam juga menghendaki pemenuhan kehidupany ang baik dan terhormat bagi setiap manusia melalui proses pemberdayaan.AllahSWTbersabda: 
“ barang siapa yang mengerjakan amalsaleh, baik laki-laki maupunperempuan dalam keadaan beriman, maka sesungguhnya akan kami berikan kepadanya kehidupan yangbaikdan sesungguhnyaakankami beri alasankepada merekadengan pahalayang lebih baikdari apayang telahmerekakerjakan".(QSAn- Nahl:9

Islam tidak pernah melarang seorang istri ikut membansuaminyadalam mencari nafkah,bahkan dianjurkan.Istri Nabi Saw,Siti Aisyah dan Khadijah juga membantu Nabi dalam menopang ekonomi keluarga.Dan walaupun istri juga diboleh kan turut mencari nafkah,peran seorang istri hanya untuk membantu.Kewajiban suamilah untuk menghidupi keluarganya. Akan tetapi dalam keadaan darurat,istri boleh- boleh saja tampil dan berperan sebagai tulang punggun g keluarga dalam mencari nafkah, mengingat ada nyaa njuran dalam agama tentang kewajiban seorang muslim untuk menolong dan membantu muslim lainnya.Bekerja nya sang ibu,berarti sumber pemasukan keluarga tidak hanya satu,melainkan dua.Dengan demikian,pasangan tersebut dapat mengupayakan kualitas hidup yang lebih baik untuk keluarga,seperti dalam hal gizi, pendidikan, tempat tinggal,sandang, liburan dan hiburan, serta fasilitas kesehatan.

Tuntutan zaman menyebabkan wanita yang meninggalkan keluarga untuk bekerja semakin menonjol. Sering kali bukan semata-mata untuk mencukupi kebutuhan hidup saja wanita harus bekerja, tetapi juga didorong oleh faktor-faktor lainnya seperti untuk meningkatkan status sosial. 24 . Seperti hal nya pria yang ingin dihormati dan diakui status dan kedudukannya baik dilingkungan keluarga maupun didalam masyarakat,wanitapun memiliki hasrat yang sama untuk diakui. Dan dengan semakin tinggi nya jabatan atau kedudukan seorang wanita karir ditempat dia bekerja, akan semakin meningkatkan status sosial, penghargaan serta penghormatan masyarakat terhadap dirinya.

Setiap manusia, termasuk para ibu, mempunyai kebutuhan untuk menjalin relasi sosial dengan orang lain.Dengan bekerja,seorang wanita juga dapat memenuhi kebutuhan akan "kebersamaan"dan untuk menjadi bagian dari suatu komunitas. Bagaimana punjuga, sosialisasi penting bagi setiap orang untuk mempunyai wawasan dan cara berpikir yang luas untuk meningkatkan kemampuan empati dan kepekaan 
sosial,dan yang terpenting untuk dapat menjadi tempat pengalihan energi secara positif, dari berbagai masalah yang menimbulkan tekanan atau stress,entah masalah yang sedang dialami dengan suami,anak-anak maupun dalam pekerjaan. Dengan sejenak bertemu dengan rekan-rekan, mereka dapat saling sharing,berbagi perasaan, pandangan dan solusi. Selain karena dorongan faktor ekonomi, keberadaan wanita karir juga dimotivasi oleh kebutuhan aktualisasi diri, keinginan mempraktekkan dan memanfaatkan ilmu yang telah diperjuangkan selama bertahun-tahun di perguruantinggi.

Abraham Maslow mengembangkan teori hirarki kebutuhan,yang salah satunya mengungkapkan bahwa manusia mempunyai kebutuhan akan aktualisasi diri,dan menemukan makna hidupnya melalui aktivitas yang dijalaninya.Bekerja adalah salah satu sarana atau jalan yang dapat dipergunakan oleh manusia dalam menemukan makna hidupnya.Dengan berkarya, berkreasi, mencipta, mengekspresikan diri, mengembangkan diri dan orang lain,membagikan ilmu dan pengalaman,menemukansesuatu, menghasilkan sesuatu, serta mendapatkan penghargaan,penerimaan, prestasi-adalah bagian darip roses penemuan dan pencapaian kepenuhan diri.Kebutuhan akan aktualisasidirimelaluiprofesiatau punkarir, merupakan salah satu pilihan yang banyak diambil oleh para wanita di jaman sekarangini-terutama dengan makin terbukanya kesempatan yang sama pada wanita untuk meraih jenjang karir yang tinggi.

Seorang wanita yang bekerja (berkarir) dapat mengekspresikan dirinya,dengan cara yang kreatif dan produktif,untuk menghasilkan sesuatu dan mendatangkan kebanggaan terhadapdirinya, terutama jika prestasinya tersebut mendapatkan penghargaan danumpan balik yang positif. Wanita berusaha menemukan arti dan identitas dirinya dan pencapaian tersebut mendatangkan rasa percaya diri dan kebahagiaan.

Toto Tasmara mengatakan bahwa bekerja adalah fitrah dansekaligus merupakan salah satu identitas manusia,sehingga bekerja yang didasarkan pada prinsip-prinsip iman tauhid, bukan saja menunjukkan fitrah seorang muslim,tetapi sekaligus meninggikan martabat dirinya sebagai hamba Allah,yang mengelola seluruh alam sebagai bentuk dari cara dirinya mensyukuri kenikmatan Allah 
Islam memberi hak berkarya bagi kaum wanita sebagaimana hak bekerja bagi kaum pria.Jadi,tidak ada satu pun pekerjaan yang dihalalkan agama diharamkan atas wanita dan hanya diperbolehkan bagi kaum pria saja. Islam tidak membedakan dalam pembuatansyari'at(tasyrî') antara pria dan wanita.Hanya saja berkaitan dengan hak bekerjaini,wanita yang bersuami misalnya,ia tidak boleh bekerja tanpa persetujuan suami. Sebab, aturan keluarga dan hak-hak perkawinan menghendaki agar wanita memelihara kehidupan rumah tangga da nmementingkan kewajibansuami-istri. Diantara petunjuk Rasulullah Saw tentang keharusan seorang istri untuk meminta izin ketika ingin keluar rumah yaitu: Di riwayatkan dari Sâlimbin`Abdullah dari ayahnya dari Nabi Saw bersabda:"Apabila istri salah seorang diantara kamu mintai zin (untuk pergi ke masjid), maka janganlah dicegah".(H.R.Bukhari).

Berdasarkan hadis di atas, dikatakan bahwa sekalipun hendak pergikemasjid,istritetapharus memintaizinterlebihdahulukepada suami, apalagijika diahendakpergibekerja. Namunwanita kariryang biasabekerjadiluarrumah,iatidakperlu memintaizinkepadasuami setiapkali ia hendakpergi keluar untukbekerja, dalamarti meminta persetujuan (bolehtidaknya)iabekerja,sebabdengan bekerjanyaistridi luar rumah pastinya ia sudah mendapatkan persetujuan dari sang suami. Oleh karena itu,yang dimaksud dengan izin disinih anyalah berupa pemberitahuan istri terlebih dahulu kepada suami sebelum ia mulai bekerja.

Wanita karir harus benar-benar mampu menjaga etika Islam yang disyariatkan Allah Swt dalam menjalankan kehidupan karirnya dengan segala konsekuensinya.Hal inisangat penting terutama saat ia harus bertemu denganpriasecaraterus-menerus diruangkerja yangsama, bepergiansecara bersama-sama danlain-lain. Usahapreventif yang dapatdilakukanwanitaagartidakterjadipelanggaran-pelanggaran syariat antara lain adalah dengan berpakaian yang sopan (menutup aurat), danbersahaja dalam berbicara dan bertingkah laku Seorang wanita harus dapat menjauhi pekerjaan yang tidak sesuai dengan fitrah kewanitaannya atau dapat merusak harga dirinya. Misalnya,wanita tidak boleh bekerja dipub atau diskotik yang melayani kaum laki-laki sambil menyanyi atau menari,atau menjadi model produk tertentu yang menampakkan lekuk-lekuk tubuh untuk 
memikat para pembeli.Adapun jenis pekerjaan seperti menjadi guru, perawat,dokter, psikiater,polisiwanita,dosen,dipandang Islam sebagai pekerjaan yang sesuai dengan tabiat wanita dan kodrat kewanitaan nya.

Dengan memerhatikan uraian itu, jelaslah bahwa Islam sama sekali tidak pernah menganggap wanita hanya sebagai penganggur, atau harus di rumah saja, seperti yang dituduhkan sejumlah kalangan. "Sebaik-baik canda seorang Muslimah di rumahnya adalah bertenun," demikian sabda Nabi Muhammad SAW yang menekankan agar wanita juga harus tekun berkarya.

Meski begitu, dalam berkarir, ada tiga hal harus dipertimbangkan, yakni faktor kelemahan fisik wanita, tugas alamiahnya, serta etika yang harus ditaati. Lebih jauh, dijelaskan oleh Dr Abd al-Qadr Manshur, bahwa dengan fisik yang tidak sekuat kaum lelaki, wanita dianjurkan tidak melakukan pekerjaan berat maupun yang beresiko.

Hal ini bukan untuk menghalangi atau membatasi. Anjuran itu terkait pula dengan tugas alamiah wanita, seperti melahirkan, menyusui dan menjaga keluarga, sehingga perlu ada sinergi dengan aktivitasnya di luar rumah.

Adapun aspek etika pada dasarnya dimaksudkan untuk mengatur keseimbangan hubungan antara laki-laki dan wanita. Agama Islam sendiri mengenal yang dinamakan hukum ikthilath atau berbaurnya laki-laki dan perempuan dalam satu tempat tertentu. Ketentuan ini bisa haram, bisa mubah.

Akan menjadi haram jika mengandung tiga hal. Yakni, berduaan antara laki-laki dan wanita, terbukanya aurat wanita, serta ada persentuhan anggota badan antara lakilaki dan wanita. Namun, hukum haram ini tidak berlaku untuk mereka yang berprofesi sebagai dokter.

Jadi, tidak ada pelarangan dalam Islam terhadap kaum wanita untuk berkarir. Bahkan, banyak hadis dan pandangan ulama yang dapat dijadikan pegangan dalam melaksanakan kegiatan bermanfaat di luar rumah, tapi tentu saja harus seizin suami (bagi yang telah berkeluarga). 


\section{Penutup}

Islam adalah agama yang sangat fleksibel dan mengerti terhadap perempuan namun tetap mempunyai aturan mainnya sendiri. Dimana wanita karir dalam Islam memang diperbolehkan asalkan mendapatkan ijin dari suami dan bekerja untuk membantu keluarga, ini akan jadi sebuah kegiatan yang menyenangkan apalagi jika didasari oleh ibadah.

\section{Daftar Pustaka}

Desiree ,Auraida dan Jurfi Rizal (Ed.), Masyarakat dan Manusia DalamPembangunan,(Jakarta: PustakaSinarHarapan,1993)

Huzaemah ,T.Yanggo, Fiqh Wanita Kontemporer,(Jakarta: Almawardi Prima,2001)

Jacinta ,Rini. F..WanitaBekerja,(Jakarta: E-psikologi.com)...

Jurnal Wanita vol.56 (jakarta: yayasan jurnal wanita,2007)

Jusmaliani,2008. BisnisBerbasis Syariah, CetI, Jakarta:BumiAksara

Moekijat,PerencanaandanPengembanganKarir Pegawai,(Jakarta:C.V.RemajaKarya,1986),Cet.I,

Nasution, Khoiruddin, Fazlur Rahman Tentang Wanita, cet. Ke-1 (Yogyakarta: TAZAFFA dan ACADEMIA, 2002)

Quraish ,Shihab. M., “Konsep Wanita Menurut al-Qur'an, Hadis danSumber-Sumber Ajaran Islam", dalam Lies M.Marcoes, Wanita Islam Indonesia dalam Kajian Tekstual dan Kontekstual(Jakarta: INS,1993)

Siti, Muri"ah,WanitaKarirDalamBingkailslam,Bandung:PenerbitAngkasa, 2004,Cet.I,

Tauhid ,Dârut,KiprahMuslimahdalamKeluargaIslam,(Bandung:Mizan, 1990),Cet.I,

Toto,Tasmara o,EtosKerjaPribadiMuslim, (Yogyakarta:P.T.DanaBhaktiPrima

Wakirin . Wanita Karir Dalam Perspektif Islam. (Jurnal Prndidikan Islam Al-I'tibar Vol.4 No 1 Tahun 2017 